\title{
Co-Firing of Natural Gas with Wood Dust Experimental Test Runs
}

\author{
Maximilian KLOSE ${ }^{1 *}$, Girts VIGANTS ${ }^{2}$, Edgars VIGANTS ${ }^{3}$ \\ ${ }^{1-3}$ Institute of Energy Systems and Environment, Riga Technical University, Azenes iela 12/1, \\ Riga, Latvia
}

\begin{abstract}
Co-Firing biomass in the form of wood dust or sawdust with natural gas is a new concept, which was performed in a specialized burner from the Riga Technical University. In order to test the burner, primary experimental test runs were performed to get an overview of flue gas behaviour. The addition of sawdust increased $\mathrm{CO}$ values but $\mathrm{O}_{2}$ values remained very low in the flue gases. This was due to technical problems with the fuel. Co-Firing has the potential to reduce $\mathrm{CO}_{2}$ emissions of energy production and wood dust is an abundant byproduct of forestry, therefore the potential has to be explored in future research.
\end{abstract}

Keywords - Biomass combustion; co-firing; environmental technology; flue gases prototype; wood dust

\section{INTRODUCTION}

The country of Latvia does not possess its own natural gas deposits. Therefore, it relies heavily on the import of natural gas from other countries, such as Russia and Lithuania. In the year 2018 alone, a total of 1422 million $\mathrm{m}^{3}$ were imported over the whole year, with import rates being even higher in the winter months [2].

Therefore, becoming more independent from natural gas imports is a preferable goal. Several technologies have been shown to be able to achieve this, from renewable energy sources to more efficient resource use and smart grids. The technology of co-firing, which is presented in this paper, aims to substitute part of the use of natural gas in boilers with renewable resources, which in turn lowers the total demand for gas.

This means that two fuel mediums are combusted simultaneously. The primary fuel is fossil based and the secondary fuel, substituting some of the calorific demand, is renewable biomass or waste. Since biomass is considered to be $\mathrm{CO}_{2}$ neutral, because as plants grow, they store $\mathrm{CO}_{2}$ from the atmosphere, co-firing therefore lowers overall $\mathrm{CO}_{2}$ emissions. This can be done in already operating boilers, with minimum requirements for retrofitting. Co-firing technologies are mainly based on primary solid fuels, such as coal or primary liquid fuels like oil [6]. However, our team tested a new prototype burner, designed by the Riga Technical University, which combusts natural gas with fine sawdust. So far two papers have been published which investigated the potential of co-firing gas with biomass [3], [4] and one doctor's thesis about experiments with co-firing [5].

Wood dust is an abundant waste-product of Latvia's forestry industry and is readily available. Using it as a fuel has a lot of potential, because instead of going to landfill, it could be used as an energy resource. The aim of this paper is to look at a first test of this prototype

* Corresponding author.

E-mail address: maximilianklose@web.de 
of a burner and present initial observations that were made about flue gases. It will also present problems that were observed with the sawdust fuel and provide recommendations for the future.

\section{Methodology}

The aim of this paper is to provide experimental data from test running the specialized burner prototype. The focus was to measure the flue gases as an indicator of the combustion process behaviour. During combustion, the behaviour of the supply pipes was observed. All of this was done to see if the prototype works properly. The experiments were conducted in Jaunolaine, Latvia.

\subsection{Equipment}

The burner which is designed for the experiments is following the schematics described in Fig. 1. The maximum capacity of the burner is $20 \mathrm{MW}$. It consists of (1) a frame, (2) a gas tank, which is (3) directly connected to the inlet. The secondary fuel, which is wood dust, is stored in (4) a tank with a rotating blade where the dust slowly glides into (5) an air compressor which blows the wood dust to the (7) inlet, where the gas flows from top to bottom and wood dust is inserted after the gas has been sparked. There are also inlets that provide oxygen. The combustion happens inside the vertical reactor (8), from top to bottom. (9) Along the combustion chamber, inlets and outlets for water pipes are built into the chassis. (10) At the bottom of the burner is the exhaust pipe, beneath which a removable pan is located, which collects ash. The ash later can be removed.

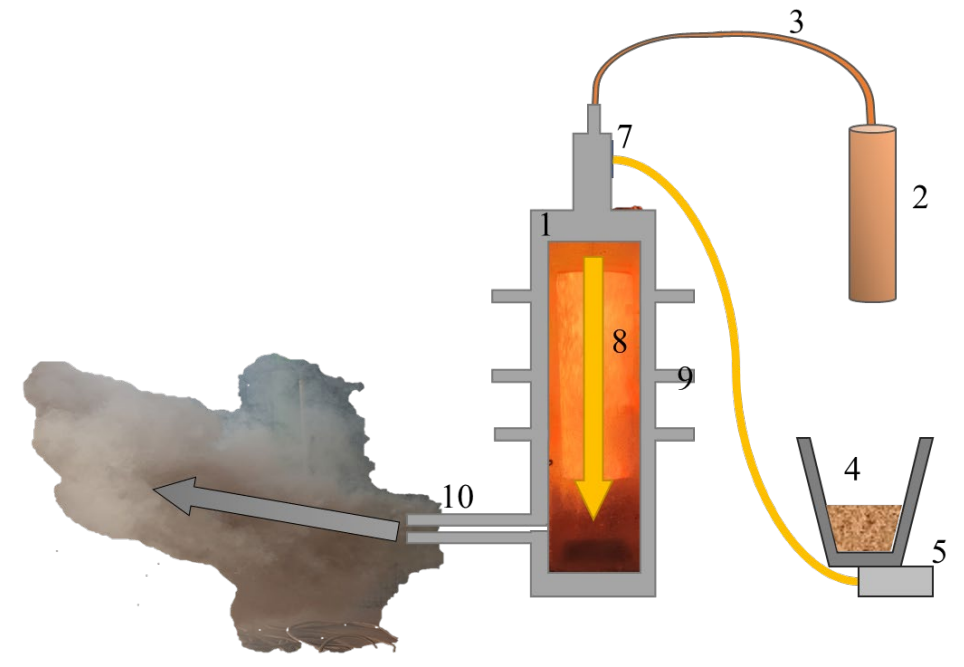

Fig. 1. Simplified schematic of the co-firing burner.

The sawdust was analysed for moisture and particle size. The samples showed that the majority (approx. 65\%) of particles were smaller than $250 \mu \mathrm{m}$. This is still above the inhalable size of $100 \mu \mathrm{m}$, below which the particles pose health hazards to the respiratory system [7]. The moisture content lay at around $6 \%$. 


\subsection{Limitations}

It is currently not possible to precisely measure the amount of wood dust which is added to the natural gas; therefore, the input variables cannot be precisely determined. This is because the tank for the wood dust does not allow a proper setup on a weight scale. The data obtained during the process will therefore be analysed by assumptions, as this paper focuses only on understanding the technical limitations of the prototype. Future experiments with a method to determine the input values will enable us to calculate the efficiency of co-firing at different levels of fuel substitution.

\subsection{Theoretical Approaches}

The idea behind co-firing is to substitute part of natural gas with biomass, because the $\mathrm{CO}_{2}$ emissions from the latter are considered to be zero. Theoretical calculations have been performed in prior CONECT papers [5] for different levels of substitution.

TABle 1. Co-Firing Parameters Under DifFerent Fuel Mixtures [5]

\begin{tabular}{llllll}
\hline Parameters & $\mathbf{1}$ & $\mathbf{2}$ & $\mathbf{3}$ & $\mathbf{4}$ & $\mathbf{5}$ \\
\hline Combustion type & Gas & Co-Firing & Co-Firing & Co-Firing & Biomass \\
Biomass substitution, $\mathrm{S}_{\mathrm{b}}, \%$ & 0 & 25 & 50 & 75 & 100 \\
Biomass capacity, MW & 0 & 0.25 & 0.5 & 0.75 & 1 \\
Gas capacity, MW & 1 & 0.75 & 0.5 & 0.25 & 0 \\
Biomass/Gas ratio, $\mathrm{r}_{\mathrm{b} / \mathrm{g}}$ & 0 & 0.33 & 1 & 3 & - \\
Biomass feed rate, $\mathrm{B}_{\mathrm{b}}, \mathrm{t} / \mathrm{h}$ & 0 & 0.0521 & 0.104 & 0.1562 & 0.208 \\
Gas feed rate, $\mathrm{B}_{\mathrm{g}}, 1000 \mathrm{Nm}^{3} / \mathrm{h}$ & 0.1052 & 0.0789 & 0.05263 & 0.0263 & 0 \\
$\mathrm{CO}_{2}$ generation, $\mathrm{tCO}_{2} / \mathrm{h}$ & 0.1976 & 0.148 & 0.0988 & 0.0494 & 0 \\
$\mathrm{CO}_{2}$ rate, $\mathrm{tCO}_{2} / \mathrm{h}, \mathrm{r}_{\mathrm{b} / \mathrm{g}}$ & - & 0.448 & 0.0988 & 0.0165 & 0 \\
\hline
\end{tabular}

Since the actual combustion of wood dust still produces $\mathrm{CO}_{2}$ in practice, adding biomass to the gas combustion should increase overall $\mathrm{CO}_{2}$ emissions. The emissions for forestry residues are, according to literature, $24 \mathrm{~g} / \mathrm{kWh}$ [1]. Therefore, if biomass is added to the combustion of gas, an increase of $\mathrm{CO}_{2}$ emissions in the flue gases should be observed, which will be checked during the test run. However, of the produced energy, a larger part is then covered by neutral $\mathrm{CO}_{2}$, since the added biomass also contributes to energy generation. In the test run, an increase of the flue gas temperature should be observed when sawdust is added. The advantage of sawdust is that the surface area of the particles is larger than that of regular biomass fuels such as woodchips or pellets. Therefore, the combustion process should theoretically run smoothly. Furthermore, the low moisture content should also allow for complete combustion. 


\subsection{Experimental Test Run}

During a test run of 15 minutes, an unidentified amount of biomass was added to the combustion of natural gas and $9 \mathrm{kWh}$ of heat energy were produced. Three observations were made, the first during the beginning of the test run while sawdust was added, the second in the middle of the combustion process and a relatively stable addition of secondary fuel and a third set during the end, when the sawdust addition slowly decreased. The behaviour of all elements was closely monitored to check for technical problems. A Testo 340 sensor tested the flue gases $\mathrm{CO}_{2}, \mathrm{O}_{2}, \mathrm{CO}$ and the flue gas temperature. It was inserted at an inlet at the exhaust pipe at the bottom. This inlet is dedicated for sensors to allow reproduction of measurements. The first observation lasted 20 seconds, the second 73 seconds and the final observation was 28 seconds. The results are collected in the graphs in the following section.

\section{EXPERimental Measures}

Fig. 1 and Fig. 2 show the behaviour of flue gases composition and temperature during the beginning of the test run. The first observation shows a decrease in flue gas temperature when biomass is added, from approximately $700{ }^{\circ} \mathrm{C}$ to around $550{ }^{\circ} \mathrm{C}$, while the amount of $\mathrm{CO}_{2}$ rises quickly from $8 \%$ and then remains at around $16 \%$, the $\mathrm{O}_{2}$ share decreases symmetrically from 12 to less than $1 \%$. It should be noted that they mirror each other during all observations.

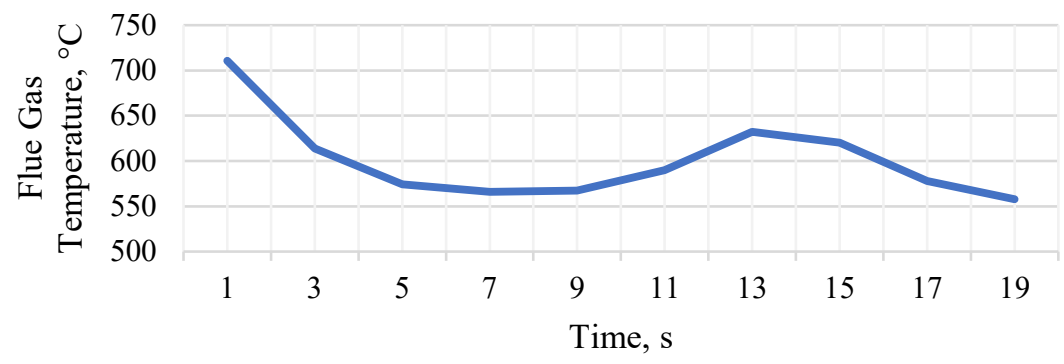

Fig. 2. Flue Gas Temperature Observation 1.

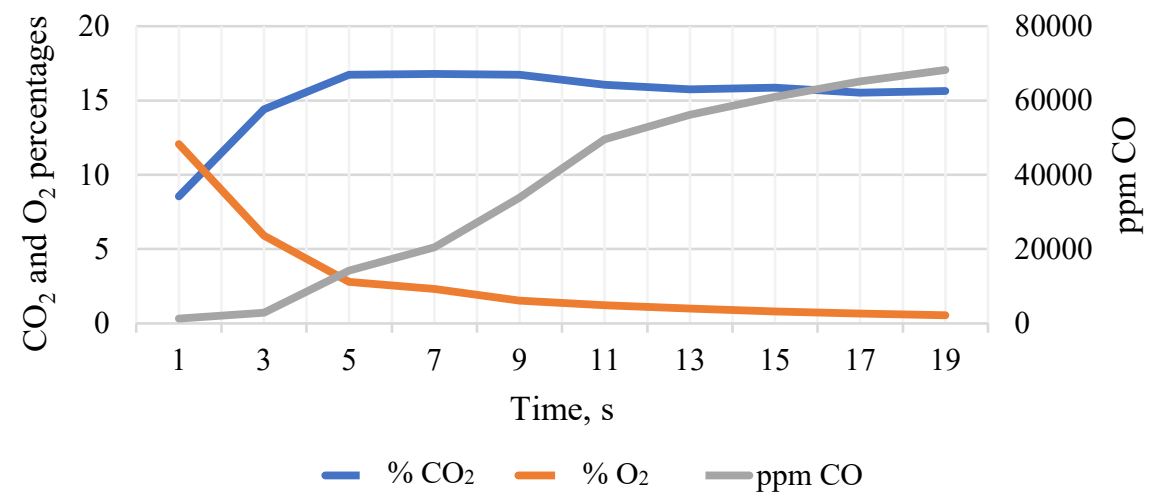

Fig. 3. Emissions Observation 1. 
The CO levels rise constantly as more wood dust is added to the reactor to $70000 \mathrm{ppm}$.

The second observation during the middle of the test run showed a steadier temperature of flue gases mainly around $700{ }^{\circ} \mathrm{C}$ (the trendline is added to the graph in Fig. 4).

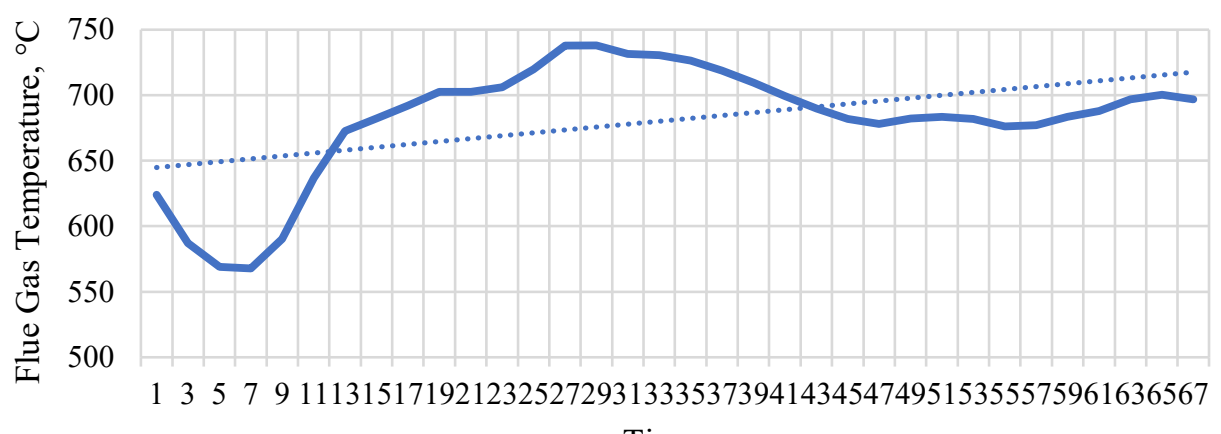

Time, $\mathrm{s}$

Temperature ${ }^{\circ} \mathrm{C} \quad \cdots \cdots . .$. Linear $\left(\right.$ Temperature ${ }^{\circ} \mathrm{C}$ )

Fig. 4. Flue Gas Temperature Observation 2.

Fig. 5 shows emissions during the second observation. $\mathrm{CO}_{2}$ flue gases remain mostly stable around $16 \%$, while $\mathrm{O}_{2}$ almost reach percentages below $1 \%$ when the amount of CO increases.

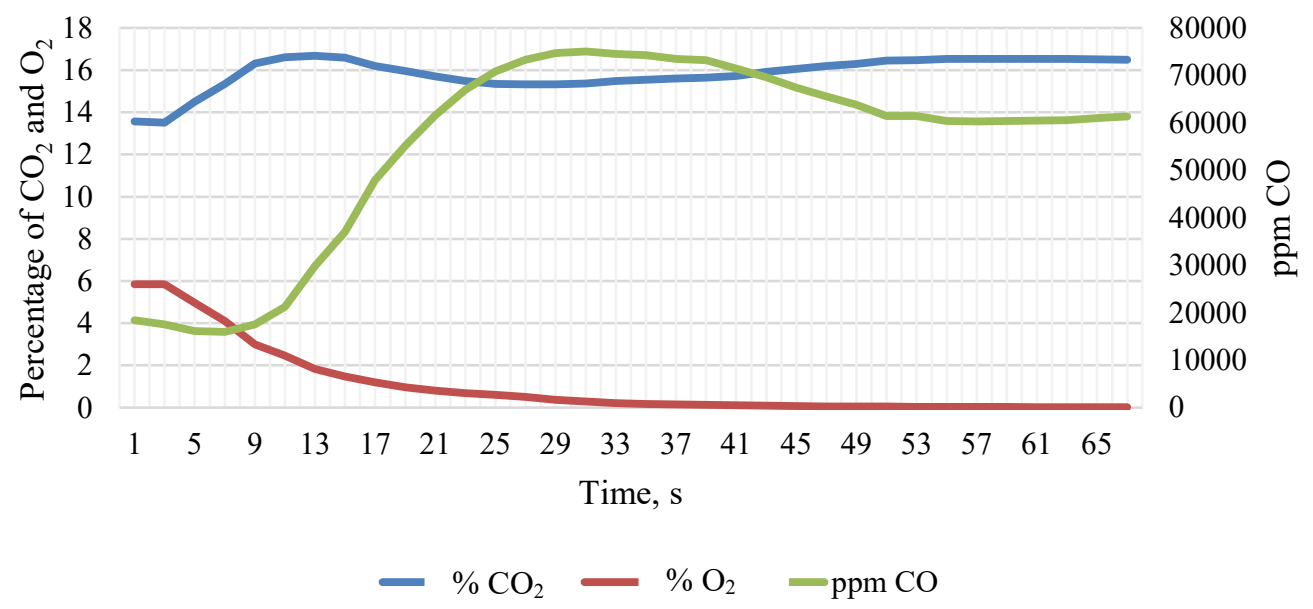

Fig. 5. Emissions Observation 2.

The final observations, shown in Fig. 6 and Fig. 7, during a decrease of the wood dust addition show maximum flue gas temperatures between $850{ }^{\circ} \mathrm{C}$ to $700{ }^{\circ} \mathrm{C}$. 


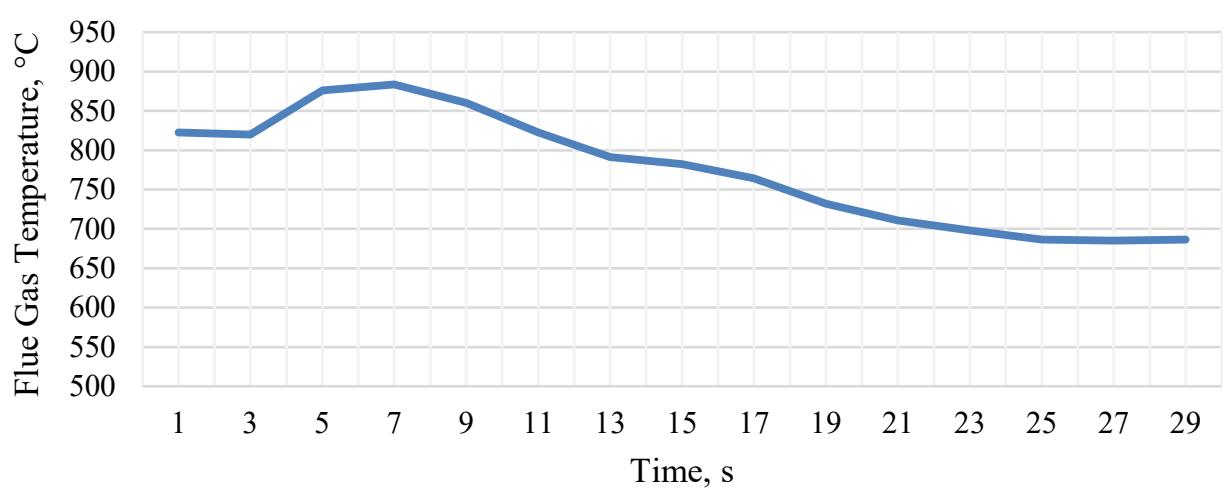

Fig. 6. Flue Gas Temperature Observation 3.

The flue gas during a decrease of wood dust shows a steady decrease of CO down to 2500 ppm, while $\mathrm{CO}_{2}$ and $\mathrm{O}_{2}$ mirror each other around $12 \%$ and $8 \%$.

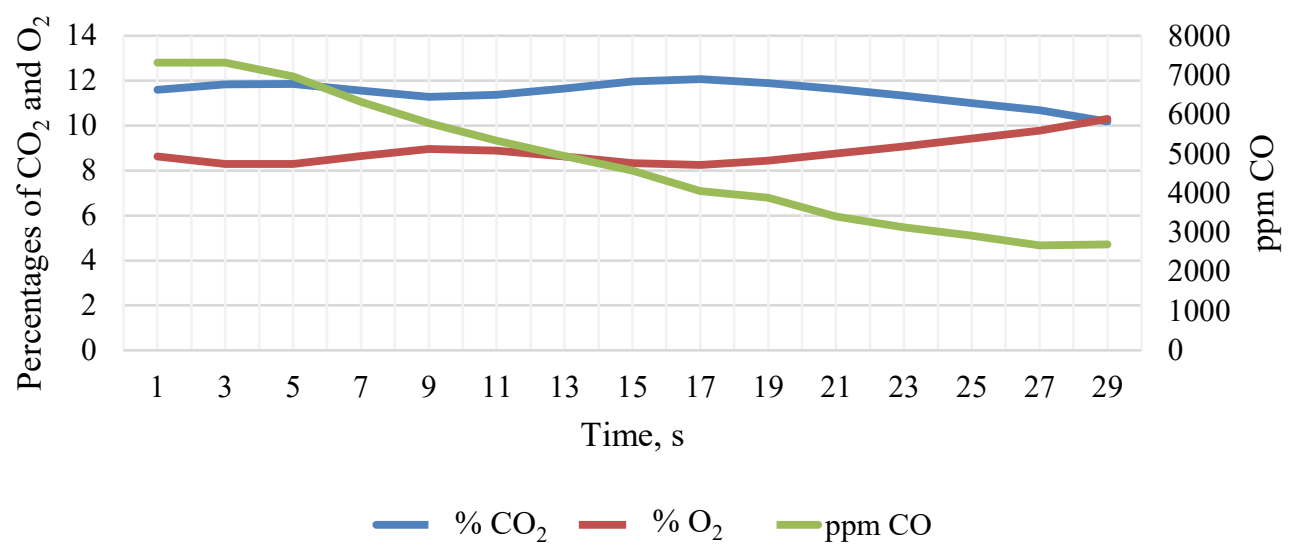

Fig. 7. Emissions Observation 3.

\section{DisCUSSION OF RESUlTS}

The boiler showed major problems with the addition of wood dust from the tank to the inlet nozzles. The wood dust congested inside the pipe and was transported in irregular bursts. This was either due to low air pressure from the compressor or leaky pipes, as well as too large of a diameter of the pipe which allowed the dust to accumulate. The addition of sawdust seems to increase the amount of $\mathrm{CO}$, as can be seen by the rise in Fig. 3, which is a sign of incomplete combustion. At the inlet nozzles, these chunks inhibit a stable input of $\mathrm{O}_{2}$. However, $\mathrm{O}_{2}$ levels remain low, which means that the high surface area of the sawdust allowed good oxidation. Flue gas temperatures also fluctuate during the whole observation due to the unstable combustion. 


\section{Conclusions}

Testing the burner clearly showed a major flaw: the sawdust is handled like a gas and pumped through pipes, where it creates congestion. This congestion creates a very unstable combustion process as can be seen by the flue gas values. A better way of adding the wood dust needs to be found to guarantee a stable combustion. The amount of $\mathrm{CO}$ is an indicator of how much sawdust was added to the burner at a specific time. $\mathrm{CO}_{2}$ emissions increased with the addition of sawdust, but since it is biomass, the overall share of neutral $\mathrm{CO}_{2}$ also increased. Overall, the burner works fine, except for the aforementioned problems at the pipes and inlet nozzle.

\section{RECOMMENDATIONS}

A possible alleviation to improve the sawdust would be to set the burner up horizontally and use pipes with a smaller diameter. A horizontal setup will set the tank and inlet nozzle on the same height, which may lower the possibility of congestions due to sawdust being pulled back by gravity. Smaller pipes will increase the air pressure inside the pipes, which will forward the sawdust better. If these problems are solved, further steps for experiments for cofiring with this burner will focus on a more specific measurement of input values and comparing the heat energy of gas-only runs with co-firing runs. Further on, different levels of fuel substitution will be tested. This means finding a way to supply the wood dust more steadily to provide a more stable combustion process in the future. Since wood dust is available in abundance in Latvia, it is a viable option for expanding co-firing additionally to wood pellet co-firing.

\section{ACKNOWLEDGEMENT}

The research is funded by the Ministry of Economics of the Republic of Latvia, project "Assessment of Latvia's renewable energy supply-demand economic potential and policy recommendations", Project No. VPP-EM-2018/AER-1-0001.

\section{REFERENCES}

[1] Boyle G. Renewable energy Power for a sustainable future. UK: Oxford University Press, 2004.

[2] Central Statistics Bureau of Latvia. Imports and consumption of natural gas $\left(\mathrm{mln} . \mathrm{m}^{3}\right)$ [Online]. [Accessed 3.11.2019]. Available: www.csb.gov.lv/en/stats_table_metadata/159/

[3] Kazulis V., Vigants H., Veidenbergs I., Blumberga D. Biomass and natural gas co-firing - evaluation of greenhouse gas emissions. Energy Procedia 2018:147:558-565. https://doi.org/10.1016/j.egypro.2018.07.071

[4] Priedniece V., et al. Biomass co-firing laboratory equipment. Energy Procedia 2016:113:390-395. https://doi.org/10.1016/j.egypro.2017.04.019

[5] Suzdalenko V. Wood Pellets Co-Firing with Gaseous Fossil Fuel. Doctoral Thesis, Riga Technical University, 2013.

[6] van Ioo S., Koppejan J. The Handbook of Biomass Combustion and Cofiring. London: Earthscan, 2008.

[7] Zhang Y. Indoor Air Quality Engineering. Florida: Boca Raton, 2004. 